\title{
Two new species of betatorqueviruses identified in a human melanoma that metastasized to the brain
}

\author{
Terry Fei Fan $\mathrm{Ng}^{1,2,3,5}$, Jennifer A. Dill ${ }^{3}$, Alvin C. Camus ${ }^{3}$, Eric Delwart ${ }^{1,2, *}$ and \\ Erwin G. Van Meir ${ }^{4, *}$ \\ ${ }^{1}$ Blood Systems Research Institute, San Francisco, California, USA \\ ${ }^{2}$ Department of Laboratory Medicine, University of California at San Francisco, San Francisco, California, USA \\ ${ }^{3}$ Department of Pathology, University of Georgia, Athens, Georgia, USA \\ ${ }^{4}$ Departments of Neurosurgery and Hematology \& Medical Oncology, Winship Cancer Institute and School of Medicine, Emory \\ University, Atlanta, Georgia, USA \\ ${ }^{5}$ Current/Present address: DVD, NCIRD, Centers for Disease Control and Prevention, Atlanta, Georgia, USA \\ *Co-senior authors \\ Correspondence to: Terry Fei Fan Ng, email: ylz9@cdc.gov \\ Keywords: brain tumor; neuro-oncology; anellovirus; metagenomics; metastasis \\ Received: September 19, 2017 \\ Accepted: October 25, 2017 \\ Published: November 11, 2017 \\ Copyright: Fan Ng et al. This is an open-access article distributed under the terms of the Creative Commons Attribution License \\ 3.0 (CC BY 3.0), which permits unrestricted use, distribution, and reproduction in any medium, provided the original author and \\ source are credited.
}

\section{ABSTRACT}

The role of viral infections in the etiology of brain cancer remains uncertain. Prior studies mostly focused on transcriptome or viral DNA integrated in tumor cells. To investigate for the presence of viral particles, we performed metagenomics sequencing on viral capsid-protected nucleic acids from 12 primary and 8 metastatic human brain tumors. One brain tumor metastasized from a skin melanoma harbored two new human anellovirus species, Torque teno mini virus Emory1 (TTMV Emory1) and Emory2 (TTMV Emory2), while the remaining 19 samples did not reveal any exogenous viral sequences. Their genomes share $63-67 \%$ identity with other TTMVs, and phylogenetic clustering supports their classification within the Betatorquevirus genus. This is the first identification of betatorqueviruses in brain tumors. The viral DNA was in its expected non-integrated circular form, and it is unclear if the viruses contributed to tumor formation. Whether the viruses originated from blood, or the primary skin tumor could not be ascertained. Overall, our results demonstrate the usefulness of viral metagenomics to detect previously unknown exogenous virus in human brain tumors. They further suggest that active viral infections are rare events in brain tumors, but support a follow-up larger scale study to quantify their frequency in different brain tumor subtypes.

\section{INTRODUCTION}

Cancers largely result from genetic mutations that induce cell transformation. While the role of some viruses in animal carcinogenesis is well established, virusmediated oncogenesis has only been shown for a small number of human cancers. These oncoviruses include human alpha papillomaviruses (mainly HPV16 and
18), Kaposi's sarcoma-associated herpesvirus (HHV8), Merkel cell polyomavirus, Epstein-Barr virus, Human T-lymphotropic virus type 1, and hepatitis B virus [1-3]. Human immunodeficiency virus (HIV) and hepatitis $\mathrm{C}$ virus (HCV) may cause cancer by more indirect mechanisms such as chronic inflammation and immunedeficiency. Genetically engineered oncolytic viruses are also being developed as therapies against brain tumors [4-6]. 
What triggers the genetic mutations that cause primary brain tumors is mostly unknown. In healthy individuals, the brain is considered a privileged organ where the blood-brain barrier prevents pathogens from entry [7], but when pathogens, including viruses, gain access by crossing the blood-brain barrier, it can lead to diseases such as encephalitis or microcephaly in developing fetuses or infants $[8,9]$. Currently, the only known virus capable of causing a brain tumor in a mammalian host is a raccoon polyomavirus [10]. No virus has definitively been demonstrated to cause primary brain tumors in human, yet a variety of viruses have been reported to be associated with primary human brain tumors, including polyomaviruses and cytomegaloviruses $[11,12]$.

Due to their location and therapeutic resistance [13], brain neoplasms are among the most challenging to treat, and biopsies can only be obtained when medically necessary. Most knowledge of virus infections in the central nervous system comes from the analysis of cerebrospinal fluid (CSF) [7]. Analyzing brain tumor tissue directly to characterize its virome is an approach rendered possible by the recent development of next generation sequencing (NGS) methods. For example, the NGS approach allowed diagnosis of a rare leptospira infection in a case of unexplained acute meningoencephalitis in a clinically relevant timeframe [14]. A recent whole genome and transcriptome study directly sequenced the DNA and RNA from 1,122 adult diffuse gliomas, but did not report any viral sequences in the glioma and associated stroma cell genomes [15]. Whole genome or transcriptome approaches focus on host genomes or endogenous/integrated viral sequences, but are less sensitive for detecting encapsidated viral genomes (Figure 1).

To address this issue, we applied a viral metagenomics approach to focus sequencing on nucleaseresistant (encapsidated) viral nucleic acids after filtration of tissue homogenates through a $400 \mathrm{~nm}$ filter $[16,17]$ (Figure 1), to investigate 20 retrospectively collected frozen human brain tumors of various types.

\section{RESULTS AND DISCUSSION}

The virome and PCR analyses identified two novel anelloviruses in a specimen from a patient with a skin melanoma that had metastasized to the brain collected in 1993 (Sample \#5) (Figures 2 and 3). Genome assembly from sequenced fragments evidenced circular viral genomes and these did not originate from cancer cell chromosomal DNA, as no contiguous viral-host genome fragments were found (Figure 2A). No viral sequences were detected in the other tumors. In-silico investigation of the entire in-house viral metagenomic database [18] of the laboratory where the NGS was performed did not detect any other samples containing sequences of these two viruses, ruling against possible lab contamination. Anelloviruses in the family Anelloviridae comprise small, non-enveloped viruses containing a single-stranded, negative-sense circular DNA genome enclosed within an icosahedral nucleocapsid. The genome of anelloviruses ranges between 2.1-3.9 kb in length. Human infections with anelloviruses are virtually ubiquitous [19-21], and vertebrate homologs have been described in various domestic animal species including dogs, cats, pigs, cows, chickens, and sheep, as well as wild non-human primates and marine mammals [22-27]. There are three known anellovirus genera that infect humans (Alphatorquevirus, Betatorquevirus and Gammatorquevirus). The Alphatorquevirus genus includes 29 species (Torque teno virus, TTV 1-29), Betatorquevirus includes 12 species (Torque teno mini virus, TTMV 1-12), and Gammatorquevirus includes 15 species (Torque teno midi virus, TTMDV 1-15) [28]. Human anelloviruses are commonly found in human blood, but can also be detected in liver, kidney, lungs, spleen, and occasionally in cerebrospinal fluid [29-31], brain tissue [30], and nerve tissue [31]. The detection of anellovirus in brain is rare; the literature mentions brain tissue from a single adult who suffered from head trauma tested positive for an Alphatorquevirus [30]. Since their discovery, human anelloviruses association with various diseases has been proposed, including hepatitis and respiratory illnesses, but strong and consistent evidence for disease association and pathogenesis in humans is lacking [20,32].

Phylogenetic analysis of the ORF1 gene, the most conserved open reading frame (ORF) among anelloviruses, showed that the two viruses clustered with other Torque teno mini viruses (Figure 2C), supporting their phylogeny in the Betatorquevirus genus. They were designated Torque teno mini virus Emory1 (TTMV Emory1, KX810063) and Torque teno mini virus Emory2 (TTMV Emory2, KX810064), and their genomes were deposited in GenBank. The genome lengths for TTMV Emory1 and Emory2 are 2,830 and 2,938 nucleotides (nt), with a GC content of $37 \%$ and $36 \%$, respectively. Both viral genomes contain the typical anelloviruses genome organization [28] (Figure 2A), with three open reading frames where ORF1 is the longest. Compared to known species of TTMV and with each other, both viruses share $33-44 \%$ amino acid identity and 62-65\% nucleotide identity (NI) in ORF1, as well as $63-67 \%$ NI in the whole genome (Figure 2B). Current International Committee on Taxonomy of Viruses (ICTV) criteria state that anelloviruses of the same species share at least $65 \%$ nucleotide identity in ORF1. Given their sequence divergence, TTMV Emory1 and Emory2 likely each represent new human anellovirus species within the genus Betatorquevirus.

This pairwise comparison, together with the phylogenetic analysis (Figure 2), strongly support that TTMV Emory1 and Emory2 are distinct taxa. The presence of two distinct anellovirus genomes in a single brain tumor supports co-infection with two anelloviruses. 
In an attempt to localize the viruses within a specific cell type within the tumors, we performed in situ hybridization (ISH) and fluorescence in situ hybridization (FISH) on frozen tumor sections post-fixed with formalin with probes specific to Emory1 and Emory2. However, results for both methods were negative (data not shown). As a control, DNA of both viruses was confirmed present by PCR in the pre-fixation frozen specimens (Figure 3 ). This suggests that the viral nucleic acid in tumor tissues was likely beyond the limits of detection of in situ hybridization, or that anelloviruses were present as viral particles in blood circulating through the tumor, which would have been lost during the fixation steps used for sample preparation. We also attempted to obtain the primary skin melanoma tumor for virome analysis, but the original samples were no longer available.

The most common intracranial neoplasms in adults originate from systemic tumors that metastasize to the brain. The most frequent are lung carcinomas $(\sim 20 \%)$, melanomas $(\sim 7 \%)$, renal cell carcinomas $(\sim 6.5 \%)$, and breast carcinomas $(\sim 5 \%)$ [33]. In this study, we investigated a variety of brain tumor types (Table 1). We only found a single tumor out of 20 to contain exogenous viral sequences (rather than human endogenous retroviruses). It is, therefore, unlikely that viruses are commonly replicating at high levels in these tumors.

Our study did not identify polyomaviruses or cytomegalovirus sequences in the filtered and nuclease treated tumor homogenates, even though these viruses were previously reported in primary human brain tumors $[11,12]$. This could be due to limited sampling, or because these hypothetical oncogenic viruses are integrated into the tumor genome after initial infection [34] - thus yielding no viral particles. The latter explanation is unlikely, as efforts aimed at detecting viral sequences in human cancer genomes confirmed human papillomavirus, hepatitis B virus and Epstein-Barr virus transcripts in carcinomas affecting the cervix, liver, or lymphocytes, but failed to identify viral sequences in human brain tumors and skin melanomas [35]. Another virome assessment using glioblastoma datasets from the Cancer Genome Atlas (TCGA) did not find anelloviruses in the tumor by

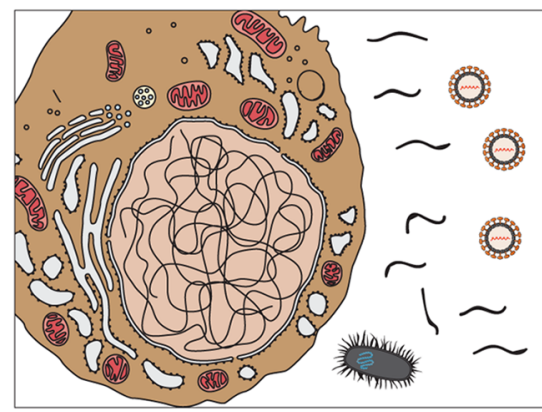

Homogenization releases cell content from tissue
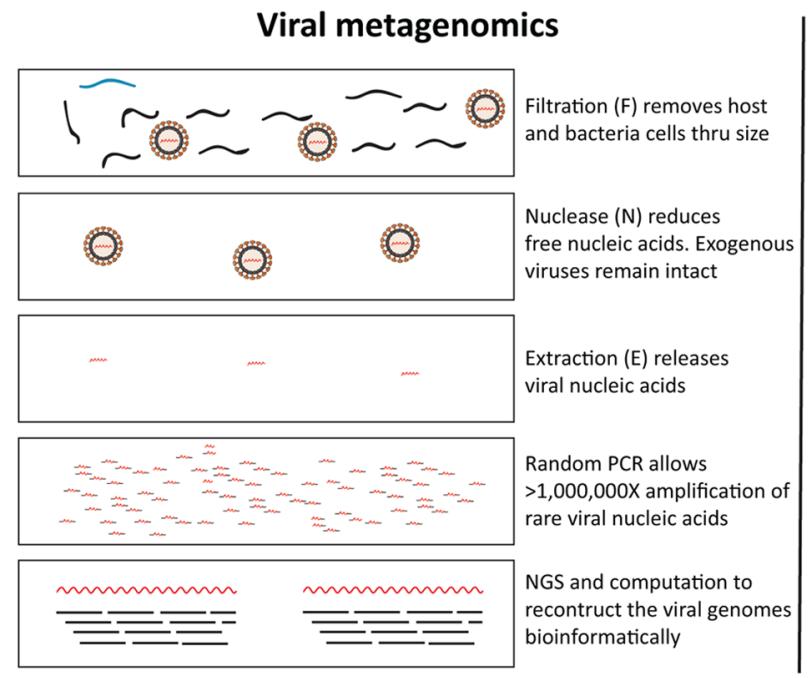

Whole genome Sequencing or Transcriptome

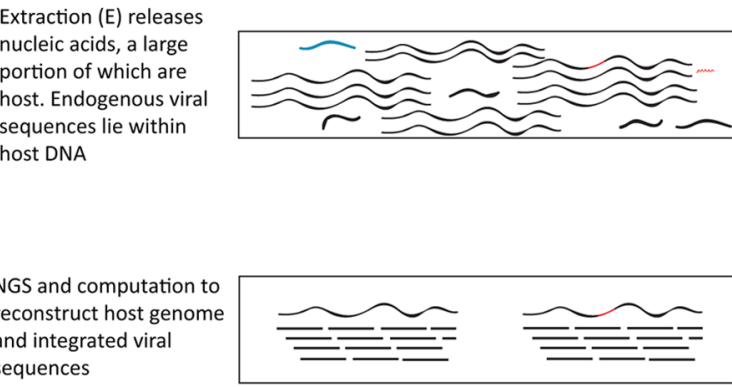

Figure 1: Schematic diagram outlines the typical viral metagenomic approach in this study, using filtration, nuclease and extraction (FNE) treatments $[16,17]$ to distinguish rare viral sequences from abundant host cell and free DNA. Black wavy lines denote host nucleic acids; blue wavy lines denote bacterial nucleic acids; red wavy lines denote viral nucleic acids. In the top panel, host (Left), bacteria (bottom), and viruses (right) are schematically represented. Viral nucleic acids are protected by viral capsids from degradation during nuclease $(\mathrm{N})$ treatments, unlike the host and bacterial nucleic acids. Obtaining rare exogenous viral sequence through viral metagenomics (bottom panel left) is different from obtaining endogenous viral genomes through transcriptome or whole genome sequencing (bottom panel right). 
A)
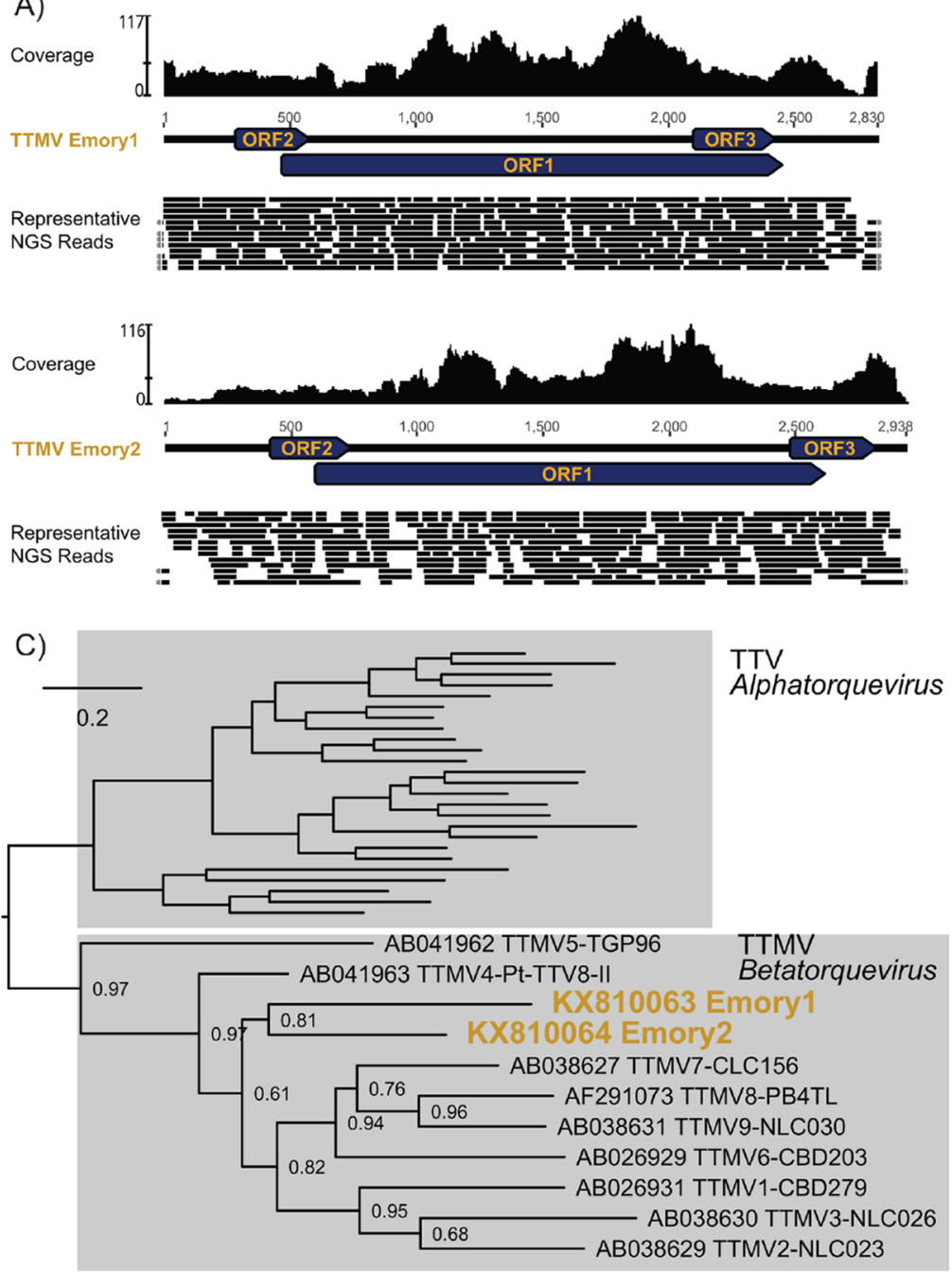

B)

Whole genome nucleotide

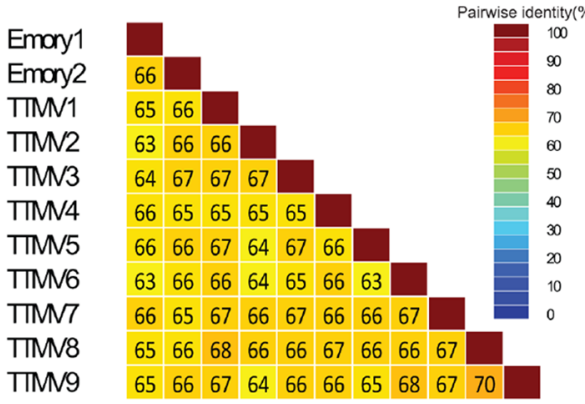

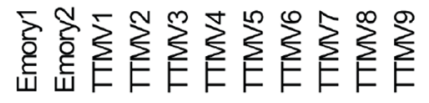

ORF1 protein

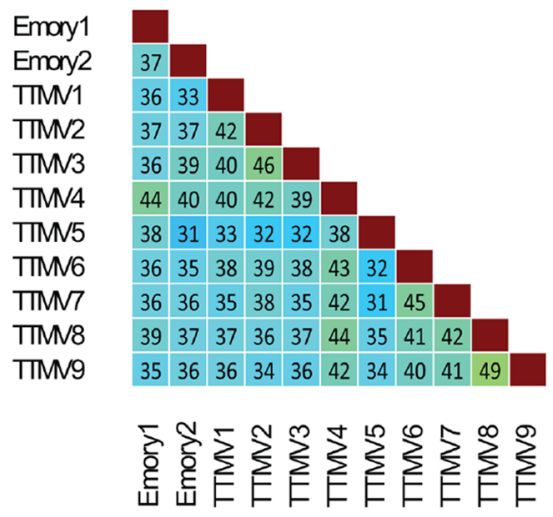

Figure 2: Comprehensive genomic and phylogenetic analysis of the Torque teno mini virus Emory1 (TTMV Emory1) and Torque teno mini virus Emory2 (TTMV Emory2). (A) Schematic depiction of the TTMV Emory1 and Emory2 genome organization. Coverage for NGS data is indicated, and a portion of the representative NGS reads is shown. The circular genome is graphically linearized for display purpose, and the reads covering across the ends are marked with grey arrows on the extremities. (B) Pairwise whole genome nucleotide identities and ORF1 amino acid identities between Torque teno mini viruses. Protein sequences were aligned with MUSLE [52], and sequence identities were calculated using the species demarcation tool [53]. (C) ORF1 protein phylogeny of the genus Betatorquevirus, including the newly described TTMV Emory1 and Emory2. Maximum likelihood phylogeny was generated with PhyML [54], where branch support was calculated using Approximate Likelihood-Ratio Test (aLRT). The scale bar represents evolutionary distance in substitutions per site.

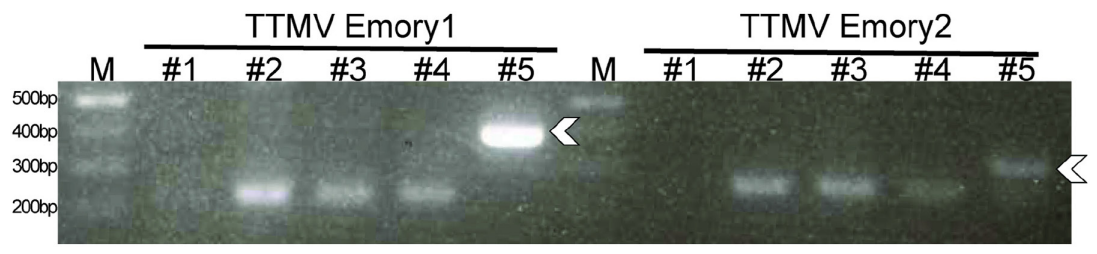

Figure 3: PCR analysis of viral DNA. Arrows denote expected amplicon. TTMV Emory 1 PCR was performed with primers Emory ${ }_{-}$ AF and Emory1_AR with an amplicon size of 387 bp. TTMV Emory 2 PCR was performed with primers Emory2_AF and Emory2_AR with an amplicon size of 332 bp. M, size markers; \#1-5, samples 1-5. Bands below the expected amplicon size were due to primers or primer dimers. 
Table 1: Human brain tumor specimens used for the study

\begin{tabular}{llcc}
\hline Sample number & Description & Age/sex & Weight \\
\hline 1 & Metastasis, Carcinoma, primary of breast origin & $49 / \mathrm{F}$ & $233 \mathrm{mg}$ \\
2 & Metastasis, Carcinoma, poorly differentiated, primary of unknown origin & $67 / \mathrm{M}$ & $270 \mathrm{mg}$ \\
3 & Metastasis, Carcinoma, poorly differentiated, primary of unknown origin & $40 / \mathrm{F}$ & $351 \mathrm{mg}$ \\
4 & Metastasis, Adenocarcinoma with lung primary & $49 / \mathrm{F}$ & $291 \mathrm{mg}$ \\
5 & Metastasis, Melanoma, malignant, primary from skin & $57 / \mathrm{M}$ & $250 \mathrm{mg}$ \\
6 & Metastasis, Melanoma, malignant, primary from skin & $51 / \mathrm{M}$ & $244 \mathrm{mg}$ \\
7 & Metastasis, Adenocarcinoma, primary of breast origin & $38 / \mathrm{F}$ & $224 \mathrm{mg}$ \\
8 & Metastasis, Carcinoma, poorly differentiated, consistent with breast primary & $67 / \mathrm{F}$ & $244 \mathrm{mg}$ \\
9 & Schwannoma (I) & $32 / \mathrm{F}$ & $264 \mathrm{mg}$ \\
10 & Schwannoma (I) & $49 / \mathrm{M}$ & $223 \mathrm{mg}$ \\
11 & Medulloblastoma (IV) & $7 / \mathrm{M}$ & $231 \mathrm{mg}$ \\
12 & Medulloblastoma (IV) & $34 / \mathrm{F}$ & $213 \mathrm{mg}$ \\
13 & Pilocytic Astrocytoma (I) & $8 / \mathrm{F}$ & $237 \mathrm{mg}$ \\
14 & Anaplastic Astrocytoma (III), recurrence from pilocytic astrocytoma (I) & $76 / \mathrm{M}$ & $225 \mathrm{mg}$ \\
15 & Glioblastoma (IV), recurrence from oligodendroglioma (II) & $44 / \mathrm{F}$ & $251 \mathrm{mg}$ \\
16 & Glioblastoma (IV) & $55 / \mathrm{M}$ & $257 \mathrm{mg}$ \\
17 & Gliosarcoma (IV) & $59 / \mathrm{M}$ & $222 \mathrm{mg}$ \\
18 & Gliosarcoma (IV) & $83 / \mathrm{F}$ & $210 \mathrm{mg}$ \\
19 & Subependymoma (I) & $77 / \mathrm{M}$ & $263 \mathrm{mg}$ \\
20 & Subependymoma (I) & $59 / \mathrm{M}$ & $243 \mathrm{mg}$ \\
\hline
\end{tabular}

WHO 2006 classification grade is indicated for primary brain tumors. Weight of frozen sample used for analysis is indicated.

nucleotide homology search [36]; however, the search database was limited to less than 40 anellovirus genomes.

Our study does not provide any evidence that the newly discovered viruses had a role in the pathogenesis of the metastatic melanoma in which they were identified. Although anelloviruses nearly universally infect humans in their lifetime, no human anellovirus has yet been shown to be oncogenic [20]. Genomes of the Anelloviridae family lack homologs of genes that promote cell transformation in other DNA viruses such as polyomaviruses or papillomaviruses, which respectively contain oncogenic proteins large T antigen and E6 and E7 that inactivate the retinoblastoma $(\mathrm{Rb})$ and $\mathrm{p} 53$ tumor suppressors. Anelloviruses are not known to integrate into host cell genomes [37], thereby excluding insertional mutagenesis. Some studies have suggested TTMVs may have indirect carcinogenic effects by modulating $\mathrm{T}$ cell immune responses, possibly through expression of specific miRNAs that inhibit the interferon response [38, 39]. If future larger scale studies confirm their presence in specific cancers, then further studies on potential oncogenic effects will be warranted.

Tumors undergo extensive angiogenesis, increasing the number of blood vessels within the neoplastic tissue [40]. The disorganized nature of the vasculature can result in increased vascular permeability and disruption of the blood-brain-barrier [41, 42], rendering the neoplastic tissue more susceptible to the extravasation of viruses from the blood, such as anelloviruses. Several studies have detected anelloviruses in cerebrospinal fluid, which directly bathes the brain [29-31]. Immunosuppression during organ transplant, HIV/AIDS, and sepsis can also cause increases in anellovirus titers circulating in the blood [43-46]. Whether anelloviruses can infect some metastatic brain tumor cells or their detection here simply reflects viremia and blood present in cancer biopsies remains to be determined.

In conclusion, our study identified two new species of betatorqueviruses and is the first demonstration of TTMVs in human brain tumor specimens. Furthermore, 
it provides proof-of-principle that metagenomic analysis can be used to identify viral genomes that are not integrated in human brain tumor genomes, likely reflecting their presence as infectious viral particles. Finally, it suggests that active virus infections are rare in human brain tumors, complementing prior studies that focused only on transcriptome or viral DNA integrated in tumor cells.

\section{MATERIALS AND METHODS}

\section{Sample collection}

We investigated 20 frozen human brain tumor samples retrospectively collected under institutional IRB approval, including primary tumors of Schwannoma, Medulloblastoma, Astrocytoma, Glioblastoma, Gliosarcoma, and Subependymoma, as well as metastases to brain from Carcinoma, Melanoma, and Adenocarcinoma (Table 1; WHO 2006 classification). The tumor specimens were collected from neurosurgeries under IRB approval, and were stored in liquid nitrogen vapor at $-130^{\circ} \mathrm{C}$. The samples were distributed into four pools, each containing five tumor samples (specimens $\# 1-5$; 6-10; 11-15 and 16-20) for viral metagenomics (Figure 1).

\section{Viral metagenomic sequencing}

Unbiased viral metagenomics sequencing of nuclease-resistant nucleic acids was performed directly according to previously described protocols that detect both DNA and RNA viruses [16, 17]. Briefly, homogenized tumor pools were filtered through $400 \mathrm{~nm}$ filters (Millipore), followed by depletion of host nucleic acids in the filtrate using DNAse and RNAse. Nuclease-resistant nucleic acids were extracted using the QIAamp Viral RNA Mini Kit (Qiagen; which extracts both DNA and RNA [47]) and sequence-independent amplification was performed using random priming. Random first strand synthesis of both DNA and cDNA was performed using Superscript IV (Invitrogen; which has both reverse transcriptase and DNA polymerase activities) and primer N1_8N 5'-CC TTGAAGGCGGACTGTGAGNNNNNNNN-3'. The second strand was synthesized using Klenow fragment DNA polymerase (New England BioLabs) using the same primer. The products from the second strand synthesis were then used as input to be randomly amplified by PCR using AmpliTaq Gold DNA polymerase and primer N1, 5'-CCTTGAAGGCGGACTGTGAG-3'. Amplified DNA were subjected to Nextera XT DNA Sample Prep kit, and sequenced using the MiSeq (Illumina) sequencing system with $2 \times 250$ bp paired-end sequencing reagents [16]. This method has been used extensively for both DNA and RNA exogenous viruses $[16,17,47]$.

\section{Bioinformatics analysis}

Sequence data was analyzed using a customized NGS pipeline as described previously [48]. First, reads identical to human and bacterial genomes were computationally subtracted $[16,17]$. The remaining reads were assembled de novo into contigs using Ensemble Assembler [48]. The contigs and the unassembled reads were then aligned to an in-house viral proteome database using BLASTx with an E-value cutoff of 0.01 . The significant sequence matches to virus were filtered again with an in-house non-virus-non-redundant (NVNR) universal proteome database using BLASTx.

Genome analysis was performed according to previously described procedures [49], including genome organization, ORF annotation, NGS coverage analysis, pairwise comparison of the ORF1 gene and whole genomes, and phylogenetic analysis. Viral sequences identified in the virome analysis were reconfirmed in the specific individual samples using PCR (Figure 3).

\section{PCR and in situ hybridization}

Specific PCR primers for each new TTMV were designed directly from the genomes obtained from the NGS data. Tumor DNA was extracted using QIAamp Viral RNA Mini kit (Qiagen). PCR was performed using primer sets specific for each virus: Emory1_AF, 5'-CGCCGAAAACCTTACAAAAA-3'; Emory1_AR, 5'-TTGGTGGTTGTGTGCTGAAT-3'; Emory2_AF, 5'-CCACCACAACAATTCCAAAA-3'; Emory2_AR, 5'-CAGTCTCCGCTCATTGGTTT-3'. PCR was carried out using the Ex Taq DNA Polymerase (Clontech) for 45 cycles using a touch down cycling condition as described before [50]: $95^{\circ} \mathrm{C}$ for $5 \mathrm{~min}, 45$ cycles of $\left[94^{\circ} \mathrm{C}\right.$ for 1 min, $58^{\circ} \mathrm{C}$ minus $0.2^{\circ} \mathrm{C}$ per cycle for $1 \mathrm{~min}, 72{ }^{\circ} \mathrm{C}$ for 3 min], followed by $72{ }^{\circ} \mathrm{C}$ for $10 \mathrm{~min}$.

In situ hybridization (ISH) and fluorescence in situ hybridization (FISH) were performed on frozen tumor sections post-fixated with formalin according to an established protocol [51]. Digoxigenin-labeled PCR probes were generated using primers specific to Emory1 and Emory2; the primers were Emory1_AF, Emory1_AR, Emory2_IF, 5'-CCAACGACCTCGAAAACATT-3'; Emory2_IR, 5'-AGTTGTCGGAGCTGCTGTTT-3'. Sections of formalin-fixed tissue were rehydrated, digested with proteinase $\mathrm{K}$ and then the probes were applied to glass slides and allowed to hybridize overnight in a $37^{\circ} \mathrm{C}$ humidified oven. After washing, sections were blocked with universal blocking buffer (BioGenex). Mouse anti-digoxigenin antibody (ROCHE) diluted 1:500 with Antibody Diluent (DAKO) was applied to the sections for 60 minutes and then washed. Detection of bound antibody was done by serial application of goat anti-mouse biotinylated immunoglobulins (Biogenex), streptavidin alkaline 
phosphatase (Biogenex), and napthol fast red substrate (DAKO), followed by mounting with aqueous adhesive. For FISH, sections were blocked with normal goat serum (Rockland), conjugated with Streptavidin-Alexa Fluor ${ }^{\circledR} 532$, and mounted with ProLong Gold with DAPI (Molecular Probes).

\section{ACKNOWLEDGMENTS}

We thank JoAnn Yates, Saroja N Devi, Zhaobin Zhang, and David Giannantonio for tumor banking, administrative support and sample logistics. We thank Nikola O. Kondov for technical support with PCR.

\section{CONFLICTS OF INTEREST}

All authors declare that they have no conflicts of interest.

\section{FUNDING}

This study was supported in part by NIH grants CA163722, NS096236 and CA138292 (to EGVM).

\section{Ethical approval}

Institutional IRB approval was obtained for use of banked human brain tumor tissue.

\section{REFERENCES}

1. Schiffman M, Castle PE, Jeronimo J, Rodriguez AC, Wacholder S. Human papillomavirus and cervical cancer. Lancet. 2007; 370:890-907.

2. Knipe D, Howley P, Griffin D, Lamb R, Martin M, Roizman B, Straus S. (2013). Fields Virology. Vol I+ II. Lippincott, Williams \& Wilkins.

3. Munoz N, Bosch FX, de Sanjose S, Herrero R, Castellsague $\mathrm{X}$, Shah KV, Snijders PJ, Meijer CJ. Epidemiologic classification of human papillomavirus types associated with cervical cancer. N Engl J Med. 2003; 348:518-527.

4. Post DE, Fulci G, Chiocca EA, Van Meir EG. Replicative oncolytic herpes simplex viruses in combination cancer therapies. Curr Gene Ther. 2004; 4:41-51.

5. Chu RL, Post DE, Khuri FR, Van Meir EG. Use of replicating oncolytic adenoviruses in combination therapy for cancer. Clin Cancer Res. 2004; 10:5299-5312.

6. Post DE, Shim H, Toussaint-Smith E, Van Meir EG. Cancer scene investigation: how a cold virus became a tumor killer. Future Oncol. 2005; 1:247-258.

7. Khwaja FW, Reed MS, Olson JJ, Schmotzer BJ, Gillespie GY, Guha A, Groves MD, Kesari S, Pohl J, Van Meir EG. Proteomic identification of biomarkers in the cerebrospinal fluid (CSF) of astrocytoma patients. J Proteome Res. 2007; 6:559-570.

8. Mlakar J, Korva M, Tul N, Popovic M, Poljsak-Prijatelj M, Mraz J, Kolenc M, Resman Rus K, Vesnaver Vipotnik T, Fabjan Vodusek V, Vizjak A, Pizem J, Petrovec M, Avsic Zupanc T. Zika virus associated with microcephaly. N Engl J Med. 2016; 374:951-958.

9. Koskiniemi M, Vaheri A. Effect of measles, mumps, rubella vaccination on pattern of encephalitis in children. Lancet. $1989 ; 1: 31-34$

10. Brostoff T, Dela Cruz FN Jr, Church ME, Woolard KD, Pesavento PA. The raccoon polyomavirus genome and tumor antigen transcription are stable and abundant in neuroglial tumors. J Virol. 2014; 88:12816-12824.

11. Alibek K, Kakpenova A, Baiken Y. Role of infectious agents in the carcinogenesis of brain and head and neck cancers. Infect Agent Cancer. 2013; 8:7.

12. White MK, Gordon J, Reiss K, Del Valle L, Croul S, Giordano A, Darbinyan A, Khalili K. Human polyomaviruses and brain tumors. Brain Res Brain Res Rev. 2005; 50:69-85.

13. Van Meir EG, Hadjipanayis CG, Norden AD, Shu HK, Wen PY, Olson JJ. Exciting new advances in neuro-oncology: the avenue to a cure for malignant glioma. CA Cancer J Clin. 2010; 60:166-193.

14. Wilson MR, Naccache SN, Samayoa E, Biagtan M, Bashir H, Yu G, Salamat SM, Somasekar S, Federman S, Miller S, Sokolic R, Garabedian E, Candotti F, et al. Actionable diagnosis of neuroleptospirosis by next-generation sequencing. N Engl J Med. 2014; 370:2408-2417.

15. Ceccarelli M, Barthel FP, Malta TM, Sabedot TS, Salama SR, Murray BA, Morozova O, Newton Y, Radenbaugh A, Pagnotta SM, Anjum S, Wang J, Manyam G, et al. Molecular profiling reveals biologically discrete subsets and pathways of progression in diffuse glioma. Cell. 2016; 164:550-563.

16. Ng TF, Kondov NO, Hayashimoto N, Uchida R, Cha Y, Beyer AI, Wong W, Pesavento PA, Suemizu H, Muench $\mathrm{MO}$, Delwart E. Identification of an astrovirus commonly infecting laboratory mice in the US and Japan. PLoS One. 2013; 8:e66937.

17. Ng TF, Marine R, Wang C, Simmonds P, Kapusinszky B, Bodhidatta L, Oderinde BS, Wommack KE, Delwart E. High variety of known and new RNA and DNA viruses of diverse origins in untreated sewage. J Virol. 2012; 86:12161-12175.

18. Ng TF, Zhang W, Sachsenröder J, Kondov NO, da Costa AC, Vega E, Holtz LR, Wu G, Wang D, Stine CO, Antonio M, Mulvaney US, Muench MO, et al. A diverse group of small circular ssDNA viral genomes in human and nonhuman primate stools. Virus Evol. 2015; 1:vev017.

19. Hino S, Miyata H. Torque teno virus (TTV): current status. Rev Med Virol. 2007; 17:45-57. 
20. Spandole S, Cimponeriu D, Berca LM, Mihăescu G. Human anelloviruses: an update of molecular, epidemiological and clinical aspects. Arch Virol. 2015; 160:893-908.

21. Okamoto H, Nishizawa T, Takahashi M, Asabe S, Tsuda F, Yoshikawa A. Heterogeneous distribution of TT virus of distinct genotypes in multiple tissues from infected humans. Virology. 2001; 288:358-368.

22. Leary TP, Erker JC, Chalmers ML, Desai SM, Mushahwar IK. Improved detection systems for TT virus reveal high prevalence in humans, non-human primates and farm animals. J Gen Virol. 1999; 80:2115-2120.

23. Verschoor EJ, Langenhuijzen S, Heeney JL. TT viruses (TTV) of non-human primates and their relationship to the human TTV genotypes. J Gen Virol. 1999; 80:2491-2499.

24. Ng TF, Suedmeyer WK, Gulland F, Wheeler E, Breitbart M. Novel anellovirus discovered from a mortality event of captive California sea lions. J Gen Virol. 2009; 90:1256-1261.

25. Ng TF, Wheeler E, Greig D, Waltzek TB, Gulland F, Breitbart M. Metagenomic identification of a novel anellovirus in Pacific harbor seal (Phoca vitulina richardsii) lung samples and its detection in samples from multiple years. J Gen Virol. 2011; 92:1318-1323.

26. Cong ME, Nichols B, Dou XG, Spelbring JE, Krawczynski K, Fields HA, Khudyakov YE. Related TT viruses in chimpanzees. Virology. 2000; 274:343-355.

27. Nishizawa $T$, Okamoto $H$, Konishi $K$, Yoshizawa H, Miyakawa Y, Mayumi M. A novel DNA virus (TTV) associated with elevated transaminase levels in posttransfusion hepatitis of unknown etiology. Biochem Biophys Res Commun. 1997; 241:92-97.

28. King AM, Lefkowitz E, Adams MJ, Carstens EB. (2011). Virus Taxonomy: Ninth Report of the International Committee on Taxonomy of Viruses. (San Diego: Elsevier).

29. Maggi F, Fornai C, Vatteroni ML, Siciliano G, Menichetti F, Tascini C, Specter S, Pistello M, Bendinelli M. Low prevalence of TT virus in the cerebrospinal fluid of viremic patients with central nervous system disorders. J Med Virol. 2001; 65:418-422.

30. Pollicino T, Raffa G, Squadrito G, Costantino L, Cacciola I, Brancatelli S, Alafaci C, Florio MG, Raimondo G. TT virus has a ubiquitous diffusion in human body tissues: analyses of paired serum and tissue samples. J Viral Hepat. 2003; 10:95-102.

31. Sospedra M, Zhao Y, zur Hausen H, Muraro PA, Hamashin C, de Villiers EM, Pinilla C, Martin R. Recognition of conserved amino acid motifs of common viruses and its role in autoimmunity. PLoS Pathog. 2005; 1:e41.

32. Cossart Y. TTV - a virus searching for a disease. J Clin Virol. 2000; 17:1-3.

33. Owonikoko TK, Arbiser J, Zelnak A, Shu HK, Shim H, Robin AM, Kalkanis SN, Whitsett TG, Salhia B, Tran NL, Ryken T, Moore MK, Egan KM, Olson JJ. Current approaches to the treatment of metastatic brain tumours. Nat Rev Clin Oncol. 2014; 11:203-222.

34. Moore PS, Chang Y. Why do viruses cause cancer? Highlights of the first century of human tumour virology. Nat Rev Cancer. 2010; 10:878-889.

35. Khoury JD, Tannir NM, Williams MD, Chen Y, Yao H, Zhang J, Thompson EJ, Meric-Bernstam F, Medeiros LJ, Weinstein JN, Su X. Landscape of DNA virus associations across human malignant cancers: analysis of 3,775 cases using RNA-Seq. J Virol. 2013; 87:8916-8926.

36. Strong MJ, Blanchard E 4th, Lin Z, Morris CA, Baddoo M, Taylor CM, Ware ML, Flemington EK. A comprehensive next generation sequencing-based virome assessment in brain tissue suggests no major virus - tumor association. Acta Neuropathol Commun. 2016; 4:71.

37. Yu Q, Shiramizu B, Nerurkar VR, Hu N, Shikuma CM, Melish ME, Cascio K, Imrie A, Lu Y, Yanagihara R. TT virus: preferential distribution in $\mathrm{CD} 19(+)$ peripheral blood mononuclear cells and lack of viral integration. J Med Virol. 2002; 66:276-284.

38. Kincaid RP, Burke JM, Cox JC, de Villiers EM, Sullivan CS. A human torque teno virus encodes a microRNA that inhibits interferon signaling. PLoS Pathog. 2013; 9:e1003818.

39. zur Hausen H, de Villiers EM. TT viruses: oncogenic or tumor-suppressive properties? Curr Top Microbiol Immunol. 2009; 331:109-116.

40. Zetter BR. Angiogenesis and tumor metastasis. Annu Rev Med. 1998; 49:407-424.

41. Brat DJ, Kaur B, Van Meir EG. Genetic modulation of hypoxia induced gene expression and angiogenesis: relevance to brain tumors. Front Biosci. 2003; 8:d100-d116.

42. Zerrouqi A, Pyrzynska B, Febbraio M, Brat DJ, Van Meir EG. P14ARF inhibits human glioblastoma-induced angiogenesis by upregulating the expression of TIMP3. J Clin Invest. 2012; 122:1283-1295.

43. Li L, Deng X, Linsuwanon P, Bangsberg D, Bwana MB, Hunt P, Martin JN, Deeks SG, Delwart E. AIDS alters the commensal plasma virome. J Virol. 2013; 87:10912-10915.

44. De Vlaminck I, Khush KK, Strehl C, Kohli B, Luikart H, Neff NF, Okamoto J, Snyder TM, Cornfield DN, Nicolls MR, Weill D, Bernstein D, Valantine HA, Quake SR. Temporal response of the human virome to immunosuppression and antiviral therapy. Cell. 2013; 155:1178-1187.

45. Schiemann M, Puchhammer-Stockl E, Eskandary F, Kohlbeck P, Rasoul-Rockenschaub S, Heilos A, Kozakowski N, Gorzer I, Kikic Z, Herkner H, Bohmig GA, Bond G. Torque Teno virus load-inverse association with antibody-mediated rejection after kidney transplantation. Transplantation. 2017; 101:360-367.

46. Gorzer I, Jaksch P, Kundi M, Seitz T, Klepetko W, Puchhammer-Stockl E. Pre-transplant plasma Torque Teno 
virus load and increase dynamics after lung transplantation. PLoS One. 2015; 10:e122975.

47. Ng TF, Chen LF, Zhou Y, Shapiro B, Stiller M, Heintzman PD, Varsani A, Kondov NO, Wong W, Deng X, Andrews TD, Moorman BJ, Meulendyk T, et al. Preservation of viral genomes in 700-y-old caribou feces from a subarctic ice patch. Proceedings of the National Academy of Sciences of the United States of America. 2014; 111:16842-16847.

48. Deng X, Naccache SN, Ng TF, Federman S, Li L, Chiu CY, Delwart E. An ensemble strategy that significantly improves de novo assembly of microbial genomes from metagenomic next-generation sequencing data. Nucleic Acids Res. 2015; 43:e46.

49. Ng TF, Wellehan JF, Coleman JK, Kondov NO, Deng X, Waltzek TB, Reuter G, Knowles NJ, Delwart E. A tortoiseinfecting picornavirus expands the host range of the family Picornaviridae. Arch Virol. 2015; 160:1319-1323.

50. Ng TF, Driscoll C, Carlos MP, Prioleau A, Schmieder R, Dwivedi B, Wong J, Cha Y, Head S, Breitbart M, Delwart
E. Distinct lineage of vesiculovirus from big brown bats, United States. Emerg Infect Dis. 2013; 19:1978-1980.

51. Dawson JE, Paddock CD, Warner CK, Greer PW, Bartlett JH, Ewing SA, Munderloh UG, Zaki SR. Tissue diagnosis of Ehrlichia chaffeensis in patients with fatal ehrlichiosis by use of immunohistochemistry, in situ hybridization, and polymerase chain reaction. Am J Trop Med Hyg. 2001; 65:603-609.

52. Edgar RC. MUSCLE: multiple sequence alignment with high accuracy and high throughput. Nucleic Acids Res. 2004; 32:1792-1797.

53. Muhire BM, Varsani A, Martin DP. SDT: a virus classification tool based on pairwise sequence alignment and identity calculation. PLoS One. 2014; 9:e108277.

54. Dereeper A, Guignon V, Blanc G, Audic S, Buffet S, Chevenet F, Dufayard JF, Guindon S, Lefort V, Lescot M, Claverie JM, Gascuel O. Phylogeny.fr: robust phylogenetic analysis for the non-specialist. Nucleic Acids Res. 2008; 36:W465-W469. 